\title{
Competition with Online and Offline Demands considering Logistics Costs Based on the Hotelling Model
}

\author{
Zhi-Hua Hu, ${ }^{1}$ Chen Wei, ${ }^{1}$ Qing Li, ${ }^{1}$ and Fan Xiao ${ }^{2}$ \\ ${ }^{1}$ Logistics Research Center, Shanghai Maritime University, Shanghai 201306, China \\ ${ }^{2}$ College of Information Engineering, Shanghai Maritime University, Shanghai 201306, China \\ Correspondence should be addressed to Zhi-Hua Hu; zhhu@shmtu.edu.cn
}

Received 8 August 2014; Accepted 7 September 2014; Published 30 September 2014

Academic Editor: Tsan-Ming Choi

Copyright (c) 2014 Zhi-Hua Hu et al. This is an open access article distributed under the Creative Commons Attribution License, which permits unrestricted use, distribution, and reproduction in any medium, provided the original work is properly cited.

\begin{abstract}
Through popular information technologies (e.g., call centers, web portal, ecommerce and social media, etc.), traditional shops change their functions for servicing online demands while still providing offline sales and services, which expand the market and the service capacity. In the Hotelling model that formulates the demand effect by considering just offline demand, the shops in a line city will locate at the center as a the result of competition by games. The online demands are met by the delivery logistics services provided by the shops with additional cost; the consumers' waiting time after their orders also affects their choices for shops. The main purpose is to study the effects of the following aspects on the shops' location competition: two logistics costs (consumers' travelling cost for offline demands and the shops' delivery logistics cost for online demands), the consumers' waiting cost for online orders, and the ratios of online demands to the whole demands. Therefore, this study primarily contributes to the literature on the formulation of these aspects by extending the Hotelling model. These features and effects are demonstrated by experiments using the extended Hotelling models.
\end{abstract}

\section{Introduction}

People usually visit and buy what they want in supermarkets, shopping centers, and plaza, whereas, accompanied by the information technology and Internet, online business has an increasing tendency. In 2009, the online retail sales of USA grew $11 \%$, while all retail sales only grew $2.5 \%$ [1]. About 154 million people had the experiences of online shopping, contributing to online retail sales of $\$ 155$ billion or $6 \%$ of total retail sales. It is forecasted that the online sales of USA will keep growing at $10 \%$ as an annual rate through 2014 to $\$ 250$ billion. In Western Europe, online retail sales are expected to grow by $11 \%$ per year, going from $€ 68$ billion in 2009 to $€ 114.5$ billion in 2014. The integration of online and offline undoubtedly brings enterprises grand profits and provides multichannels for consumers.

Under the merging of online business, there are more and more people shopping on the Internet. Without going outside, people can enjoy the service from shops or other providers all over the city. Compared to the offline business, shops may suffer an additional cost, delivering cost. According to the Hotelling model [2], competitive shops often locate in the center of a line city, and they are closed to each other. However, with the development of online business, orders may come from people all over the city and should be met in the shortest time. Obviously, the locations deduced by the Hotelling model will impose great costs on the shops for online orders. Concentrated distribution, which works well in the past time, can no longer operate perfectly for the following reasons. First, remote consumers will wait for longer time to get the ordered goods because of long traveling time, which may cause low satisfaction degrees; second, long distance makes large delivery logistics cost, which carries burdens on shops; third, shops may increase the price to sustain a good profit, which may lose some consumers and form a vicious cycle. This work extends the Hotelling model for the offline and online demands.

This work extends the Hotelling model to study the effects of combination of offline and online demands on the competition of shops. The traditional Hotelling model 
has formulated the location game considering the pricing problem and the consumers' travelling logistics costs. For online demands, the consumers may choose shops based on the prices and the waiting time after orders, although the consumers do not pay for the travelling costs by themselves. However, the shops will pay for the delivery cost for servicing the consumers that order goods online. Therefore, the shop's profit should be subtracted by the logistics cost that relates to the orders and the distances between the shops and consumers. Therefore, the indifferent location computed in the side of consumers and the profit computed in the side of shops challenge the extension of the Hotelling model. Following these clues, new models are developed for analyzing the effects of logistics cost deduced by online demands on the shops' location competition.

Considering the new situation that the combination of online and offline business promotes great success, this paper extends the Hotelling model. The logistics costs, the shops' delivery times, and the consumers' waiting times are incorporated into the extended models. In the fields including online sales and competition, this study contributes to the literature in the following points. First, based on offline business, this work considers the model combining offline and online business. Second, the logistics costs and the online demands are considered in assessing the location competition game between shops. Third, the Hotelling model is extended by simultaneously considering offline and online demands and the shops' logistics cost for delivery.

The rest of the study is organized as follows. In Section 2, there are the studies related to online and offline business, competition issues in logistics systems, and the applications of the Hotelling model. Then, in Section 3 the problem is described and the problem is formulated in Section 4. The developed models are then demonstrated and analyzed in Section 5. Finally, we conclude the study in Section 6.

\section{Related Studies}

2.1. Online and Offline Business. Since the early 1990s, many manufacturers and retailers have incorporated the Internet into their multichannel strategy and devoted considerable resources to building the online channel. Chu et al. [1] thought that the Internet substantially reduces search costs and grants easy access to product and price information. Online shopping involves no travel, product carrying, or restrictions on shopping hours, offering great accessibility, convenience, and time saving. In contrast, offline shopping allows physical examination of the products, interpersonal communication, and instant gratification but involves high travel costs and search costs and often has restrictions on shopping hours, especially in countries with strong labor laws. Shankar et al. [3] claimed that the online business offers more opportunities for interactive and personalized marketing than offline business. Moreover, the online consumers can compare alternatives easily especially for functional products and services. Kwon and Lennon [4] suggested the synergy between online and offline operations generated by the seamless integration between the two channels. Kwon and
Lennon believed that the synergy enriches the consumers' experiences with the retailer, strengthens the brand image of the retailer, and cultivates consumer loyalty in both channels.

The offline and online business impose complex effects on the consumers' loyalty. Loureiro and Roschk [5] devised a model that compares the offline and online shops and regards the consumers' ages as a moderator. In the offline context, positive emotions predict loyalty among younger consumers but not among older ones; in the online context, the effect of graphics design on loyalty is stronger for younger consumers than for older ones. Kwon and Lennon [4] investigated the effect of the interplay between a multichannel retailer's offline and online brand images on consumers' online perceived risk and online loyalty within the framework of a theory of cognitive dissonance. Shankar et al. [3] proposed a conceptual framework and developed hypotheses about the effects of the online medium on consumer satisfaction and loyalty and on the relationships between satisfaction and loyalty. The results showed that loyalty to the shops is higher when the service is chosen online than offline. Besides, loyalty and satisfaction have a reciprocal relationship such that each positively reinforces the other, and this relationship between overall satisfaction and loyalty is further strengthened online.

The consumers' behaviors in the online business context are examined by many researchers. Kollmann et al. [6] identified relevant shopping motives in multichannel environments. The empirical analysis suggested that the degree of consumers' convenience orientation in contrast to the degree of risk aversion and service orientation encourages the online channel over the offline channel. Chu et al. [1] studied the moderating effects of household (e.g., shopping frequency) and product (e.g., sensory nature) characteristics on household brand loyalty, size loyalty, and price sensitivity across online and offline channels for grocery products. Households are more brand-loyal, more size-loyal but less price sensitive in the online channel than in the offline channel. The differences between online and offline business in brand loyalty and price sensitivity are large for light online shoppers and smallest for heavy online shoppers. The online and offline differences in brand loyalty, size loyalty, and price sensitivity are large for food products and for sensory products. Ahn et al. [7] explored some online and offline features of Internet shopping malls and their relationships with the acceptance behaviors of consumers, and they provide a domain-specific, integrative approach in evaluating the quality and antecedents of user acceptance for Internet shopping malls. Technology acceptance model [8] is valid in predicting the acceptance of the Internet shopping malls and that online and offline features have positive effects on the user acceptance. Both online and offline features have greater effects on the usefulness, attitude, and intention to use than either online or offline features separately.

Grewal et al. [9] provided an overview of findings from past research in both offline and online domains and presents an organizing framework, as well as an agenda to advance the research. The issues on the online and offline pricing and promotional strategies, as well as coordinating these strategies, are highlighted. This work also incorporated the 
pricing strategy in studying the location competition affected by logistics costs.

2.2. Competition in Logistics. The competitions involved in the operations and management of the supply chains are extensively examined in literature. Farahani et al. [8] considered that the competitive supply chain network design affects its cost as well as its performance and asserted that supply chains compete to capture market shares for themselves. Barney et al. [10] proposed a resource-based competition method to assess and determine the important resources and operations of a firm. In this strategic management framework, firms are viewed as entities which possess and control complex resources. The resources are scarce or unique, substitutable, and durable, which are thought to contribute to the firm's competitive advantage. Moreover, the logistic service can be regarded as a special resource so that it is also important in the firms' decisions. Papachristos [11] concerned the market competitions between new and remanufactured products and explored the environmental impact of competition on the shift from products to services with a system dynamics model. Rezapour and Farahani [12] designed the network structure of a competitive supply chain based on a bilevel model. The price and service levels competition in market are considered in the model of stochastic price and service demands with the presence of existing and external rivals. The supply chain network is assumed to be set at first and could be adjusted for new prices and services. Nagurney et al. [13] developed a game theory model for supply chain competition in time-sensitive markets where consumers are sensitive to the delivery time. An algorithm is devised to solve the model with equilibrium conditions.

The location game is a typical kind of competition between firms. Gao et al. [14] considered the location-thenprice game as a two-stage game of $n$ players on the graph which is abstracted from the spread of the firms in the real world. Based on the best response dynamics and the multinomial logit model, the price and location equilibria are built and shares of $n$ players are computed by price equilibrium. The location and price equilibria are derived for the competitive airlines in Russian and Chinese airline market. Godinho and Dias [15] addressed a discrete competitive location game in which two decision makers have to decide simultaneously where to locate their services without knowing the decisions of each other. Obviously, the decisions made by one firm will affect the payoffs of another. A model and algorithmic approach are designed to calculate the Nash equilibria in both preferential rights overbidding consuming patterns for franchisees and franchisers. The results are advantageous for the franchiser if the overbidding is possible. Fotakis and Tzamos [16] studied the facility location games where a number of facilities are set in a metric space based on the locations reported by the strategic agents. The agents minimize their connection cost to the facilities; however, the locations may be misreported by the agents. The model based on the winner-imposing mechanisms is designed to produce the mechanisms for the agents and facilities under the presumption that no agent can benefit from misreporting his location. A continuous metric space is also considered for the oblivious winner-imposing mechanisms. Some papers consider the competitions in transportations during the logistics' activities. For example, Reyes [17] studied the transshipment problem based on the Shapley value concept from the cooperative game theory by considering logistics cost and quality.

This work studied the location competition between shops with offline and online demands by considering logistics costs. The shops can gain competition advantage by improving logistics services.

2.3. Hoteling Model. Since Hotelling [2] developed the twostage game of spatial competition model, a lot of relevant literatures are gradually emerging. Considering that no equilibrium price solution exists when both firms are not far enough from each other, d'Aspremont et al. [18] replaced the linear transportation cost function with quadratic function, such that a price equilibrium solution exists everywhere. d'Aspremont concluded that the two firms gathering in the center will make the equilibrium price zero. Another way to solve the equilibrium problem is to change the city's shape to circular [19] or square [20]. By introducing consumer differentiation, increasing the number of firms, and relaxing the assumption of demand elasticity and product differentiation, the Hotelling model is extended by Tabuchi and Thiees [21], Palma et al. [22], Eaton [23], and Shaked and Sutton [24]. The researches on the applications of the Hotelling model can be divided into two classes. One solves the problem of selecting location and pricing for the product. Wey and Hong [25] extended the Hotelling model for determining the locations and the optimal numbers of plants for the purpose of using rice straws. Gao et al. [14] applied the Hotelling model to the study of the competition in airline market, where airlines first decide plane allocation and then choose ticket prices. The existence of equilibrium in pure strategies on the graph for the case of multiple plays is extensively discussed. Using distance to measure product features like quality, for firms, the Hotelling model is used to decide the product quality and brand positioning and so forth. Blosh and Manceau [26] added advertising investment in the Hotelling model and asserted that advertising makes consumers prefer products, while also decreasing the price. Therefore, advertising investment is not always necessary for firms. Based on the Hotelling model, Mariñoso [27] proved that endogenous switching costs will increase the market competition, so that the firms should produce compatible brand products.

To investigate the effects of the business mode combining offline and online demands on the location competition, the Hotelling model is extended by the following ways. First, in the consumer aspects, for online orders, the consumers' waiting cost is formulated to determine the indifferent location; second, the profit of a firm is subtracted by the delivery logistics cost for the online demands; third, the offline and online demands are considered in the integrated Hotelling 
model for studying the effect of the ratio of online demand on the competition.

\section{Problem Description}

Hotelling's linear city model was developed by Harold Hotelling in his article "Stability in Competition" in 1929 [2]. In this model he introduced the notions of locational equilibrium in a duopoly in which two firms have to choose their location considering consumers' distribution and transportation costs. Initially, the model was developed as a game in which firms first choose a location and after a selling price for their products. To set their business in the best location to maximize profits, the firms have to evaluate three key variables: competitors' location, consumers' distribution, and transportation costs. This model includes two different approaches. First, the static approach consists of a single stage, where firms choose their location and prices simultaneously; second, the dynamic one considers that the price is set after determining the location. The model is based on a linear city that consists of only a single straight street. For easy comprehension, the Hotelling model is sometimes explained by using the example of a beach where two ice cream stands are trying to decide their best locations.

3.1. Static Approach. In a beach going from west to east, of size $[0,1]$, where consumers are distributed evenly, two identical ice cream stands (A and $\mathrm{B}$ ) with a marginal cost of production, $c>0$, try to determine their best location. $A$ is located at a distance $a$ from point 0 , while $B$ is located at a distance $b$ from point 1 . Both ice cream stands offer the exact same ice creams, and therefore consumers' utility will be given only by the price of the ice cream and the distance to the stand. Despite differences in prices $\left(P_{1}\right.$ and $\left.P_{2}\right)$, the stand with the lowest prices will not necessarily attract all the demands since consumers consider the distance to the stands. If both stands' prices are equal, the differential factor is how close consumers are to each stand. All consumers located to the left of $a$ would go to stand A, and all consumers located to the right of $(1-b)$ would go to stand $B$. The remaining consumers, located between both stands, would go to whichever is the closest. Here, $x$ is the exact middle of that beach, so consumers to its left would go to stand A, while consumers to its right would go to stand B. Two conditions are necessary for profits to be positive and maximized in both stands: selling prices must be higher than marginal costs; $a \neq 1-b$. This second condition implies that both stands cannot be located at the same point exactly in the middle of the beach. If this position is indifferent for the consumers, each stand would decrease its prices to attract consumers, and thus they would enter into a price war. If they had different marginal costs, the stand with the highest marginal cost would be in a clear disadvantage and would end up exiting the market, as the other stand would be able to push the prices further down and so attract all consumers. Depending on how prices are set, the prices of both stands are equal to their marginal costs. In this approach the key factor for product differentiation is location. Each stand will therefore set prices that will be higher than their marginal costs and will choose a location other than the middle of the beach.

3.2. Dynamic Approach. The dynamic approach has two stages. At first, the stands choose their location and then the prices are set. With regard to the previous approach two additional assumptions are introduced: both stands have equal marginal production cost; total cost for consumers depends on the price of the goods and the distance to the selected stands (the unit travelling cost is $t$ ). The point of division between the areas served by these two stands is determined by the condition that at a certain point it is indifferent for consumers to choose either one of the stands. After equating and equalizing, (1) is got. By solving it, the demand functions of the two stands are (2):

$$
\begin{gathered}
p_{1}+t(x-a)=p_{2}+t((1-b)-x), \\
D_{1}=x=\frac{p_{2}-p_{1}}{2 t}+\frac{(1-b)+a}{2}, \\
D_{2}=1-x .
\end{gathered}
$$

By using backward induction the subgame perfect Nash equilibrium can be found where both firms maximize their profits.

The dynamic approach has two opposite effects. First, an incentive for both stands to locate at the center of the beach increases their market share by reaching out the greatest amount of consumers, in what is known as the demand effect. And, an incentive for both stands to locate at opposite extremes exists, in what is considered to be the strategic effect. While the first effect will reduce differentiation between the stands, the second one will increase it.

This study considers the demand effect of two shops in a line city on their locations. However, activated by the offline and online sales patterns in the fast food industry, this work considers additional online orders based on the Hotelling model. The two shops sell goods at their locations when consumers come to their shops while they also accept online orders and deliver the goods to the consumers. However, the shops will overtake the delivery logistics costs. In the above static and dynamic approaches, when the consumers order the goods offline by going to the shops, the consumers themselves must undertake the travelling cost $(t)$. Therefore, in the proposed problem in this study, as the main difference to the above Hotelling models, for online demands the shops undertake the logistics cost (delivery), and for offline demands the consumers undertake the logistics costs (travelling). Under the demand effect, two shops will locate at the center of the city. The effect of the consideration of online demands and logistics on the models is focused on in this work. 


\section{Formulation}

\subsection{Baseline Model Only considering Offline Demands}

4.1.1. Shops Locating at the Ends of the Line City. In this analysis, $p_{i}$ represents the price of shop $i, i=1,2$. The demand of shop $i$ at $p_{i}$ is denoted by $D_{i}\left(p_{1}, p_{2}\right)$. The point $x$ is the indifferent location of the consumer to buy from shop 1 or shop 2. And the unit travel cost for consumer is denoted by $t$.

Assumption 1. The commodities from both shops are homogeneous; that is, the commodity cost $c$ is the same for both shops.

Assumption 2. Without loss of generality, assume that each consumer purchases a single commodity at once.

Assumption 3. Shops in the line city are profit-oriented sellers; that is, profits of the shops should be positive.

Based on Assumptions 1 and 2, the propositions below are proposed.

Proposition 4. A consumer chooses the less cost shop in the offline baseline situation; that is, the consumer on the left of $x$ chooses shop 1 and on the right chooses shop 2 .

Proposition 4 suggests an economical consumer behavior that consumer prefers the less cost commodity. In the offline mode, consumers have to pay for the price of the commodity and the travel cost to the shop (no matter shop 1 or 2). Assuming that the travel cost is linear with the distance, $x$ is obtained by

$$
p_{1}+t x=p_{2}+t(1-x)
$$

Proposition 5. In the offline baseline situation, the Nash equilibrium exists in the profits of the shops and the equilibrium profits are $\pi_{1}^{\text {off }}=\pi_{2}^{\text {off }}=t / 2$.

In the context of the line city model, $x$ is between the positions 0 and 1 . Hence, the demand $D_{i}\left(p_{1}, p_{2}\right)$ is determined as

$$
\begin{gathered}
D_{1}\left(p_{1}, p_{2}\right)=x=\frac{p_{2}-p_{1}+t}{2 t}, \\
D_{2}\left(p_{1}, p_{2}\right)=1-x=\frac{p_{1}-p_{2}+t}{2 t} .
\end{gathered}
$$

According to the price $p_{i}$ and $D_{i}\left(p_{1}, p_{2}\right)$, the profit $\pi_{i}^{\text {off }}$ of shop $i$ is evaluated by

$$
\begin{aligned}
\pi_{1}^{\text {off }}\left(p_{1}, p_{2}\right) & =\left(p_{1}-c\right) D_{1}^{\text {off }}\left(p_{1}, p_{2}\right) \\
& =\frac{1}{2 t}\left(p_{1}-c\right)\left(p_{2}-p_{1}+t\right) \\
\pi_{2}^{\text {off }}\left(p_{1}, p_{2}\right) & =\left(p_{2}-c\right) D_{2}^{\text {off }}\left(p_{1}, p_{2}\right) \\
& =\frac{1}{2 t}\left(p_{2}-c\right)\left(p_{1}-p_{2}+t\right)
\end{aligned}
$$

To get a positive profit as defined in Assumption $3, \pi_{i}^{\text {off }}$ is positive so that $p_{i}$ is higher than $c$. We get the first order conditions of (5) on the price in the pricing game between shops 1 and 2 as

$$
\begin{aligned}
& \frac{\partial \pi_{1}^{\mathrm{off}}}{\partial p_{1}}=p_{2}+c+t-2 p_{1}, \\
& \frac{\partial \pi_{1}^{\mathrm{off}}}{\partial p_{2}}=p_{1}+c+t-2 p_{2} .
\end{aligned}
$$

Moreover, the second order conditions of (5) are

$$
\frac{\partial^{2} \pi_{1}^{\mathrm{off}}}{\partial p_{1}^{2}}=\frac{\partial^{2} \pi_{1}^{\mathrm{off}}}{\partial p_{2}^{2}}=-2
$$

So the Nash equilibrium profits exists where (8) is satisfied:

$$
\begin{aligned}
& \frac{\partial \pi_{1}^{\text {off }}}{\partial p_{1}}=p_{2}+c+t-2 p_{1}=0 \\
& \frac{\partial \pi_{1}^{\text {off }}}{\partial p_{2}}=p_{1}+c+t-2 p_{2}=0 .
\end{aligned}
$$

And the equilibrium prices and profits of both shops are

$$
\begin{aligned}
& p_{1}^{*}=p_{2}^{*}=c+t, \\
& \pi_{1}^{\text {off }}=\pi_{2}^{\text {off }}=\frac{t}{2} .
\end{aligned}
$$

4.1.2. Shops Locating at the Arbitrary Positions of the Line City. In the following, the shops can locate at any arbitrary positions of the line city. The location of shop 1 is $a \geq 0$, while the location of shop 2 is $1-b$.

Assumption 6. Without loss of generality, it is assumed that $1-a-b \geq 0$ (the shop 1 is on the left of the shop 2).

Considering consumer's quadratic travelling cost (the traveling cost is $t d^{2}$, where $d$ is the traveling distance from the consumer position to the shop stand), then the indifferent position $x$ is obtained by

$$
p_{1}^{*}+(x-a)^{2} t=p_{2}^{*}+(1-x-b)^{2} t .
$$

Proposition 7. In the arbitrary position situation, the Nash equilibrium exists in the profits of the shops, where $p_{1}^{*}=c+t(1-$ $a-b)(1+((a-b) / 3))$ and $p_{2}^{*}=c+t(1-a-b)(1+((b-a) / 3)) \cdot p_{1}^{*}$ and $p_{2}^{*}$ are the equilibrium prices of shops 1 and 2 , respectively.

As the result of (10), we get the value of $x$ by

$$
x=a+\frac{1-a-b}{2}+\frac{p_{2}-p_{1}}{2 t(1-a-b)} .
$$

Similar to the baseline city situation, the demands of both shops are derived as

$$
\begin{gathered}
D_{1}\left(p_{1}, p_{2}\right)=x=a+\frac{1-a-b}{2}+\frac{p_{2}-p_{1}}{2 t(1-a-b)}, \\
D_{2}\left(p_{1}, p_{2}\right)=1-x=b+\frac{1-a-b}{2}+\frac{p_{1}-p_{2}}{2 t(1-a-b)} .
\end{gathered}
$$


Because the positions of the shops are flexible, (12) is more complex than (4). Demand in arbitrary position situation is determined by five parameters, that is, positions $a, b$, prices $p_{1}, p_{2}$, and travel cost $t$. The profits are derived as

$$
\begin{aligned}
\pi_{1}\left(p_{1}, p_{2}\right) & =\left(p_{1}-c\right) D_{1}\left(p_{1}, p_{2}\right) \\
& =\left(p_{1}-c\right)\left(a+\frac{1-a-b}{2}+\frac{p_{2}-p_{1}}{2 t(1-a-b)}\right), \\
\pi_{2}\left(p_{1}, p_{2}\right) & =\left(p_{2}-c\right) D_{2}\left(p_{1}, p_{2}\right) \\
& =\left(p_{2}-c\right)\left(b+\frac{1-a-b}{2}+\frac{p_{1}-p_{2}}{2 t(1-a-b)}\right) .
\end{aligned}
$$

Analyzing the first-order and second-order derivatives of (13) on the prices, the results are presented as

$$
\begin{gathered}
\frac{\partial \pi_{1}}{\partial p_{1}}=a+\frac{1-a-b}{2}+\frac{p_{2}-2 p_{1}}{2 t(1-a-b)}+\frac{c}{2 t(1-a-b)}, \\
\frac{\partial \pi_{2}}{\partial p_{2}}=b+\frac{1-a-b}{2}+\frac{p_{1}-2 p_{2}}{2 t(1-a-b)}+\frac{c}{2 t(1-a-b)}, \\
\frac{\partial^{2} \pi_{1}}{\partial p_{1}^{2}}=\frac{-2}{2 t(1-a-b)}, \\
\frac{\partial^{2} \pi_{2}}{\partial p_{2}^{2}}=\frac{-2}{2 t(1-a-b)},
\end{gathered}
$$

According to Assumption 6, the values of the first-order derivatives (see (14)) are varying from positive to negative while the values of the second-order derivatives (see (15)) are negative. So the Nash equilibrium exists (see (16)):

$$
\frac{\partial \pi_{1}}{\partial p_{1}}=\frac{\partial \pi_{2}}{\partial p_{2}}=0 .
$$

The prices at equilibrium are solved as

$$
\begin{aligned}
& p_{1}^{*}(a, b)=c+t(1-a-b)\left(1+\frac{a-b}{3}\right), \\
& p_{2}^{*}(a, b)=c+t(1-a-b)\left(1+\frac{b-a}{3}\right) .
\end{aligned}
$$

In the above solution, when the first-order derivative is derived for the profit to the price, the results will be different for the conditions that $p_{1}, p_{2}, a, b$ are independent of each other; namely,

$$
\frac{\partial a}{\partial p_{1}}=\frac{\partial b}{\partial p_{1}}=\frac{\partial p_{2}}{\partial p_{1}}=0 .
$$

When $a=b=0$, the shop 1 locates at 0 while the shop 2 locates at 1 ; when $a=1-b$, two shops locate at the same position. The equilibrium prices under these two conditions are (19) and (20) individually:

$$
\begin{gathered}
p_{1}^{*}(0,1)=p_{2}^{*}(0,1)=c+t, \\
p_{1}^{*}(a, 1-a)=p_{2}^{*}(a, 1-a)=c .
\end{gathered}
$$

4.2. Extension Model for Online Consumer Demands. Based on the models in Section 4.1 for only considering offline demands, this section develops models for the online demands when considering the shops' delivery logistics costs. Similar to Section 4.1, two levels are considered, first for the shops locating at the ends of the line city and second for deciding locations for the shops. Two additional parameters are introduced for the online demands and delivery logistics: the cost of waiting for a unit of time is denoted by $c^{w}$; and the distribution cost for travelling for a unit of time is denoted by $c^{d}$.

\subsubsection{Shops Locating at the Ends of the Line City}

Proposition 8. In the online shopping situation, a consumer prefers the less cost shop based on the commodity cost and penalty costs of waiting; that is, if consumers are on the left of the indifferent position $x^{o n}=\left(p_{2}-p_{1}\right) / c^{w}+1 / 2$, they choose shop 1, while others choose shop 2 .

In the perspective of consumers, they choose online shops not according to their travelling costs to the shops, but according to the penalty costs deduced by waiting times. Therefore, the indifferent position $x$ should satisfy (21) and is derived as

$$
\begin{gathered}
p_{1}+c^{w}\left(x^{\text {on }}\right)^{2}=p_{2}+c^{w}\left(1-x^{\text {on }}\right)^{2}, \\
x^{\text {on }}=\frac{p_{2}-p_{1}}{c^{w}}+\frac{1}{2} .
\end{gathered}
$$

Similar to (4), the demands for the shops are derived as

$$
\begin{aligned}
& D_{1}^{\text {on }}=\frac{p_{2}-p_{1}}{c^{w}}+\frac{1}{2}, \\
& D_{2}^{\text {on }}=\frac{p_{1}-p_{2}}{c^{w}}+\frac{1}{2} .
\end{aligned}
$$

However, different from the offline mode, the travel cost for the consumer is substituted by the delivery logistics costs for the shops. Therefore, the profits functions of the shops are different (comparing to (5)), as shown in

$$
\begin{aligned}
\pi_{1}^{\text {on }}= & \int_{0}^{x^{\text {on }}}\left(p_{1}-c-c^{d} x\right) d x \\
= & p_{1} x-c x-\left.\frac{c^{d} x^{2}}{2}\right|_{0} ^{\left(p_{2}-p_{1}\right) / c^{w}+(1 / 2)} \\
= & p_{1}\left(\frac{p_{2}-p_{1}}{c^{w}}+\frac{1}{2}\right)-c\left(\frac{p_{2}-p_{1}}{c^{w}}+\frac{1}{2}\right) \\
& -\frac{c^{d}}{2}\left(\frac{p_{2}-p_{1}}{c^{w}}+\frac{1}{2}\right)^{2},
\end{aligned}
$$




$$
\begin{aligned}
\pi_{2}^{\text {on }}= & \int_{x^{\text {on }}}^{1}\left(p_{2}-c-c^{d}(1-x)\right) d x \\
= & p_{2} x-c x-c^{d} x+\left.\frac{c^{d} x^{2}}{2}\right|_{\left(p_{2}-p_{1}\right) / c^{w}+(1 / 2)} ^{1} \\
= & \left(p_{2}-c-c^{d}\right)\left(\frac{p_{1}-p_{2}}{c^{w}}+\frac{1}{2}\right) \\
& +\frac{c^{d}}{2}\left(1-\left(\frac{p_{2}-p_{1}}{c^{w}}+\frac{1}{2}\right)^{2}\right) .
\end{aligned}
$$

Proposition 9. In the online shopping situation, the Nash equilibrium exists in the profits of the shops where equilibrium prices are $p_{1}^{*}=p_{2}^{*}=c+\left(c^{w} / 2\right)+\left(c^{d} / 2\right)$.

As seen in (24), the profits should be subtracted by the delivery logistics cost ( $\operatorname{see} c^{d} x$ and $c^{d}(1-x)$ in the equations). When $p_{1}, p_{2}, c, c^{d}$ are independent of each other, the firstorder derivatives of the profits on the prices are shown in

$$
\begin{aligned}
& \frac{\partial \pi_{1}^{\mathrm{on}}}{\partial p_{1}}=\frac{1}{2}-\frac{2 p_{1}}{c^{w}}+\frac{p_{2}}{c^{w}}+\frac{c}{c^{w}}+\frac{c^{d}}{c^{w}}\left(\frac{p_{2}-p_{1}}{c^{w}}+\frac{1}{2}\right), \\
& \frac{\partial \pi_{2}^{\mathrm{on}}}{\partial p_{2}}=\frac{1}{2}-\frac{2 p_{2}}{c^{w}}+\frac{p_{1}}{c^{w}}+\frac{c}{c^{w}}+\frac{c^{d}}{c^{w}}\left(\frac{p_{1}-p_{2}}{c^{w}}+\frac{1}{2}\right) .
\end{aligned}
$$

It is found that the second-order derivatives of the profits on the prices are negative, because $c^{w}$ and $c^{d}$ are both positive in (26). So the optimal prices which are equilibrium prices for both shops under the maximization of the profits are derived as

$$
\begin{gathered}
\frac{\partial^{2} \pi_{1}^{\text {on }}}{\partial p_{1}^{2}}=\frac{\partial^{2} \pi_{2}^{\text {on }}}{\partial p_{2}^{2}}=-\frac{2}{c^{w}}-\frac{c^{d}}{\left(c^{w}\right)^{2}}, \\
p_{1}^{*}=c+\frac{c^{w}}{2}+\frac{c^{d}}{2}, \\
p_{2}^{*}=c+\frac{c^{w}}{2}+\frac{c^{d}}{2} .
\end{gathered}
$$

\subsubsection{Shops Locating at Arbitrary Positions of the Line City}

Proposition 10. In the online shopping situation where shops are at arbitrary positions, the Nash equilibrium exists in the profits of the shops.

In the following, the shop locations are decisions and can locate at arbitrary positions of the line city. Then, the indifferent position $x$ is derived by (28) and (29). The derivation processes in (30)-(33) are similar to (11)-(17) but the analytic expressions are more complex:

$$
\begin{gathered}
p_{1}+c^{w}\left(x^{\text {on }}-a\right)^{2}=p_{2}+c^{w}\left(1-x^{\text {on }}-b\right)^{2}, \\
x^{\text {on }}=a+\frac{1-a-b}{2}+\frac{p_{2}-p_{1}}{2 c^{w}(1-a-b)},
\end{gathered}
$$

$$
\begin{aligned}
& D_{1}^{\text {on }}=x^{\text {on }}=a+\frac{1-a-b}{2}+\frac{p_{2}-p_{1}}{2 c^{w}(1-a-b)}, \\
& D_{2}^{\text {on }}=1-x^{\text {on }}=b+\frac{1-a-b}{2}+\frac{p_{1}-p_{2}}{2 c^{w}(1-a-b)} \text {, } \\
& \pi_{1}^{\mathrm{on}}=\int_{0}^{a}\left(p_{1}-c-(a-x) c^{d}\right) d x \\
& +\int_{a}^{x^{\text {on }}}\left(p_{1}-c-c^{d}(x-a)\right) d x \\
& =\left(p_{1}-c\right)\left(a+\frac{1-a-b}{2}+\frac{p_{2}-p_{1}}{2 c^{w}(1-a-b)}\right) \\
& -a^{2} c^{d}+c^{d} a^{2} \\
& -c^{d}\left(a+\frac{1-a-b}{2}+\frac{p_{2}-p_{1}}{2 c^{w}(1-a-b)}\right)^{2} \times 2^{-1}, \\
& \pi_{2}^{\text {on }}=\int_{x^{\text {on }}}^{1-b}\left(p_{2}-c-c^{d}(1-b-x)\right) d x \\
& +\int_{1-b}^{1}\left(p_{2}-c-c^{d}(x-(1-b))\right) d x \\
& =\left(p_{2}-c\right)\left(\frac{1-a+b}{2}-\frac{p_{2}-p_{1}}{2 c^{w}(1-a-b)}\right) \\
& +\left(c^{d} b-c^{d}\right) \\
& \times\left(1-b-\left(a+\frac{1-a-b}{2}+\frac{p_{2}-p_{1}}{2 c^{w}(1-a-b)}\right)\right) \\
& +\left(c^{d}(1-b)^{2}\right. \\
& \left.-c^{d}\left(a+\frac{1-a-b}{2}+\frac{p_{2}-p_{1}}{2 c^{w}(1-a-b)}\right)^{2}\right) \times 2^{-1} \\
& +\left(c^{d}-c^{d} b\right) b-\frac{c^{d}-c^{d}(1-b)^{2}}{2}, \\
& \frac{\partial \pi_{1}^{\text {on }}}{\partial p_{1}}=\left(a+\frac{1-a-b}{2}+\frac{p_{2}-p_{1}}{2 c^{w}(1-a-b)}\right) \\
& -\frac{\left(p_{1}-c\right)}{2 c^{w}(1-a-b)}+\frac{c^{d}}{2 c^{w}(1-a-b)} \\
& \times\left(a+\frac{1-a-b}{2}+\frac{p_{2}-p_{1}}{2 c^{w}(1-a-b)}\right), \\
& \frac{\partial \pi_{2}^{\text {on }}}{\partial p_{2}}=\left(\frac{1-a+b}{2}-\frac{p_{2}-p_{1}}{2 c^{w}(1-a-b)}\right)-\frac{\left(p_{2}-c\right)}{2 c^{w}(1-a-b)} \\
& +\frac{\left(c^{d} b-c^{d}\right)}{2 c^{w}(1-a-b)}-\frac{c^{d}}{2 c^{w}(1-a-b)} \\
& \times\left(a+\frac{1-a-b}{2}+\frac{p_{2}-p_{1}}{2 c^{w}(1-a-b)}\right),
\end{aligned}
$$




$$
\begin{aligned}
& p_{1}^{*}=\left(c^{w}(1-a-b)(3-a-3 b)+3 c\right. \\
& \left.+\frac{c^{d}}{2}(b+a+1)+\frac{c^{d}\left(2 c+c^{d} b-c^{d}\right)}{2 c^{w}(1-a-b)}\right) \\
& \cdot\left(\frac{c^{w}(1-a-b)}{3 c^{w}(1-a-b)+c^{d}}\right) \\
& p_{2}^{*}=2 c^{w}(1-a-b)+2 c+c^{d} b-c^{d} \\
& -\left(c^{w}(1-a-b)(3-a-3 b)+3 c\right. \\
& \left.+\frac{c^{d}}{2}(b+a+1)+\frac{c^{d}\left(2 c+c^{d} b-c^{d}\right)}{2 c^{w}(1-a-b)}\right) \\
& \cdot\left(\frac{c^{w}(1-a-b)}{3 c^{w}(1-a-b)+c^{d}}\right) \text {. }
\end{aligned}
$$

\subsection{Model for Online and Offline Demands}

Proposition 11. In the mixed mode of online and offline, the profit is the combination of the online and offline profits according to a rate of online consumers and offline consumers, and the Nash equilibrium exists.

The shops finally considered simultaneously serve for offline and online demands. A demand has the possibility of $c^{\text {on }}$ to order goods by online methods such that the possibility of offline demand is $\left(1-c^{\text {on }}\right)$. Here, the online and offline demands are independent of each other; the introduction of online channel will not increase the total demand. Based on the models in Sections 4.1 and 4.2, the profit model for online and offline demands is derived as

$$
\begin{aligned}
& \pi_{1}=c^{\text {on }} \pi_{1}^{\text {on }}+\left(1-c^{\text {on }}\right) \pi_{1}^{\text {off }}, \\
& \pi_{2}=c^{\text {on }} \pi_{2}^{\text {on }}+\left(1-c^{\text {on }}\right) \pi_{2}^{\text {off }},
\end{aligned}
$$

where,

$$
\begin{aligned}
\pi_{1}^{\text {on }}= & \int_{0}^{a}\left(p_{1}-c-c^{d} x\right) d x \\
& \quad+\int_{a}^{x^{\text {on }}}\left(p_{1}-c-c^{d}(x-a)\right) d x \\
\pi_{2}^{\text {on }}= & \int_{x^{\text {on }}}^{1-b}\left(p_{2}-c-c^{d}(1-b-x)\right) d x \\
& \quad+\int_{1-b}^{1}\left(p_{2}-c-c^{d}(x-1+b)\right) d x \\
\pi_{1}^{\text {off }}= & x^{\text {off }} p_{1} \\
\pi_{2}^{\text {off }}= & \left(1-x^{\text {off }}\right) p_{2} .
\end{aligned}
$$

When $c^{\text {on }}$ is fixed, the equilibrium prices and profits can be derived by combining the results in Sections 4.1 and 4.2.

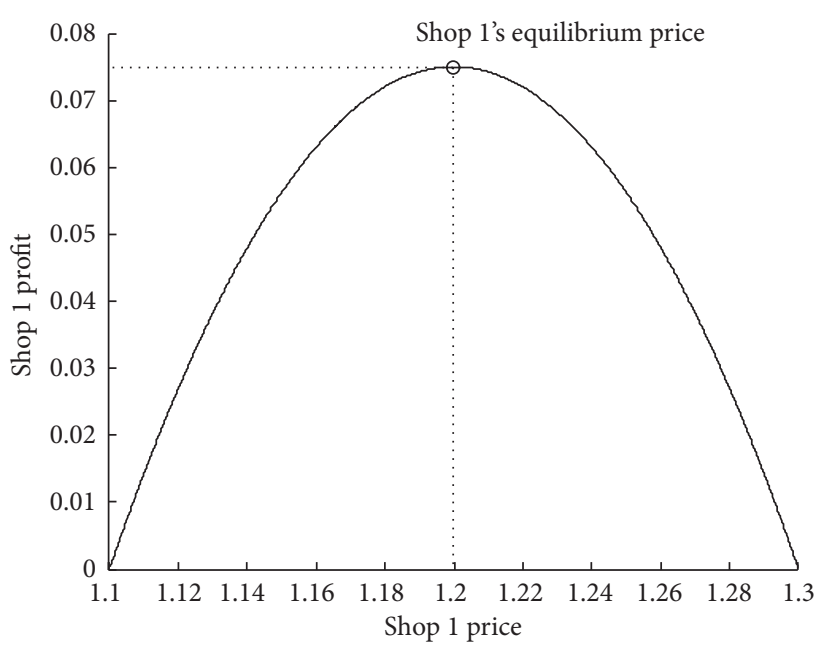

FIGURE 1: Relation between price and profit for shop 1 when shop 2 uses equilibrium price.

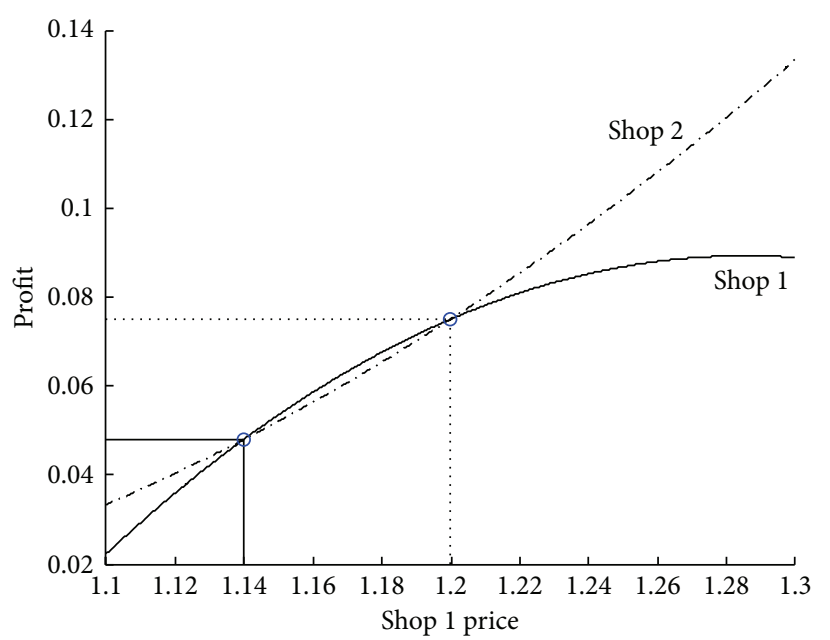

FIGURe 2: Profit curves of two shops when shop 2 decides its price following pricing of shop 1 .

\section{Experimental Results}

In the following, the models in Sections 4.2.1, 4.2.2, and 4.3 are demonstrated.

5.1. Online Shops Locating at the Ends of the Line City. The following experiments use the settings $c=1, c^{w}=0.2$, and $c^{d}=0.2$. Figure 1 presents the fact that the shop 1's profit varies with the price when the shop 2's price is the equilibrium price. It is seen that when the shop 1 deviates from the equilibrium price, its profit falls.

Figure 2 presents the profit curves for the two shops when the shop 2 determines its price following the pricing decision of shop 1. Changing the price from the equilibrium price by the shop 1 will incur the profit increase for shop 2 when shop 2 undertakes the following pricing strategy. Under this strategy, when shop 1 decreases its price to get competitive position in the price interval (1.14 to 1.2), shop 1 can get minor advantage 


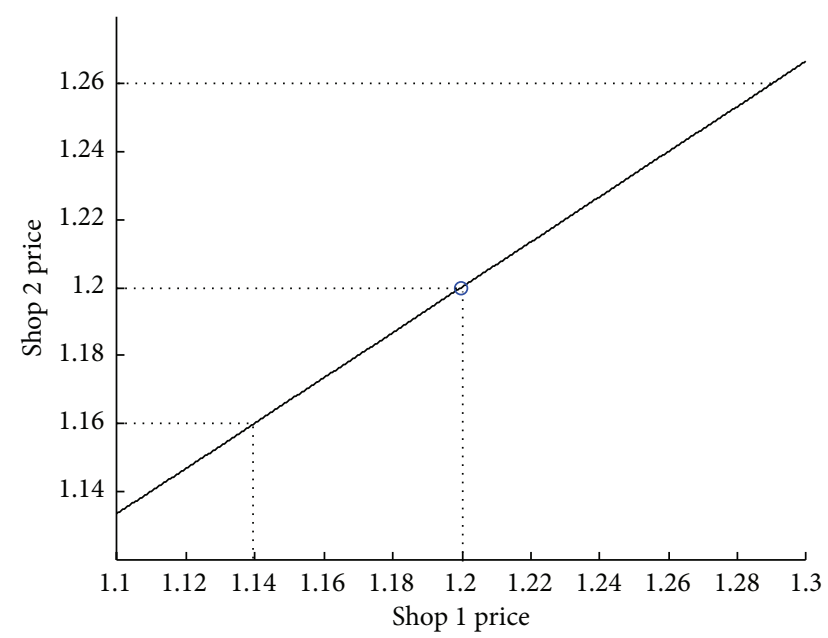

FIgURE 3: Relation between prices of two shops when shop 2 decides its price following shop 1 .

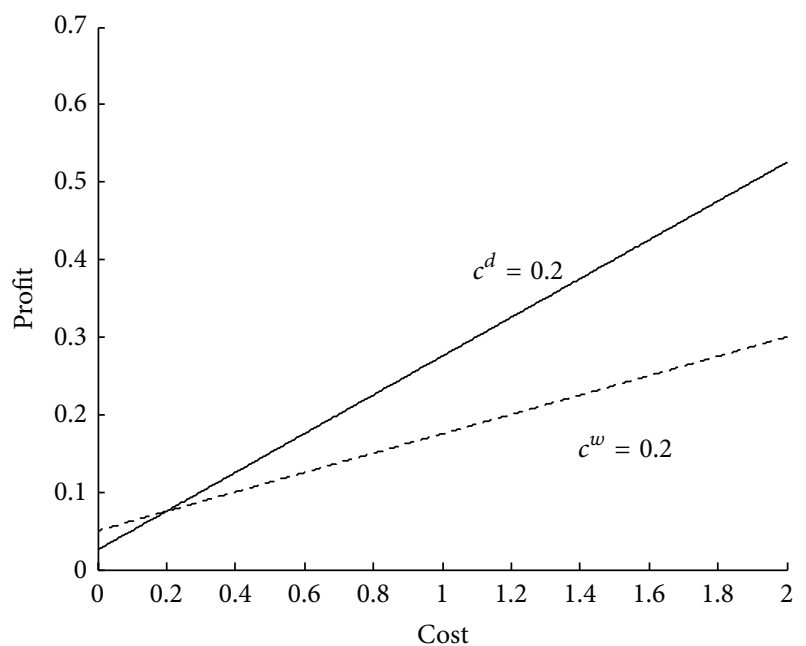

FIGURE 4: Equilibrium profits varying with waiting cost and delivery logistics cost.

comparing to shop 2 while its profit also decreases. In the other intervals (from 1.1 to 1.14 and from 1.2 to infinite values), shop 1 will lose its competitive capability. Figure 3 further depicts the fact that the shop 2's optimal price is linear to the shop l's price under the above described conditions.

Figure 4 presents the result of sensitivity analysis when the equilibrium profit varies with the cost parameters $\left(c^{w}\right.$ and $\left.c^{d}\right)$. In the experiment, one cost varies when the other is set to 0.2 . In this study, the delivery logistics cost is linear to the travelling time from the shops to consumers, whereas the waiting cost is linear to the quadric of the waiting time (which is the time travelling from the shop to the consumer). Therefore, the effect of varying unit delivery logistics cost on the equilibrium profit is larger than that of varying the unit waiting cost. The impacts of varying the unit waiting and delivery logistics costs on the equilibrium profit are shown in Figure 5.

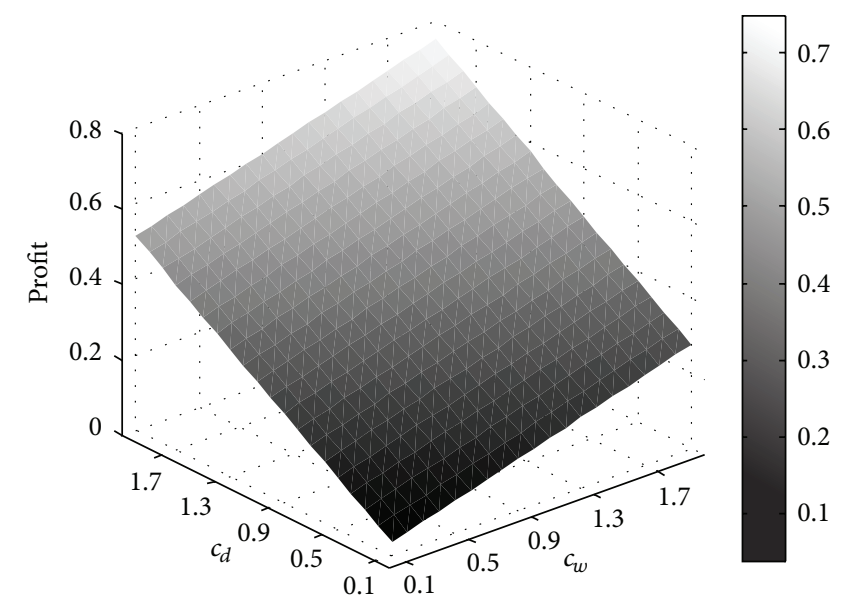

FIGURE 5: Impacts of varying unit waiting and delivery logistics costs on equilibrium profit.

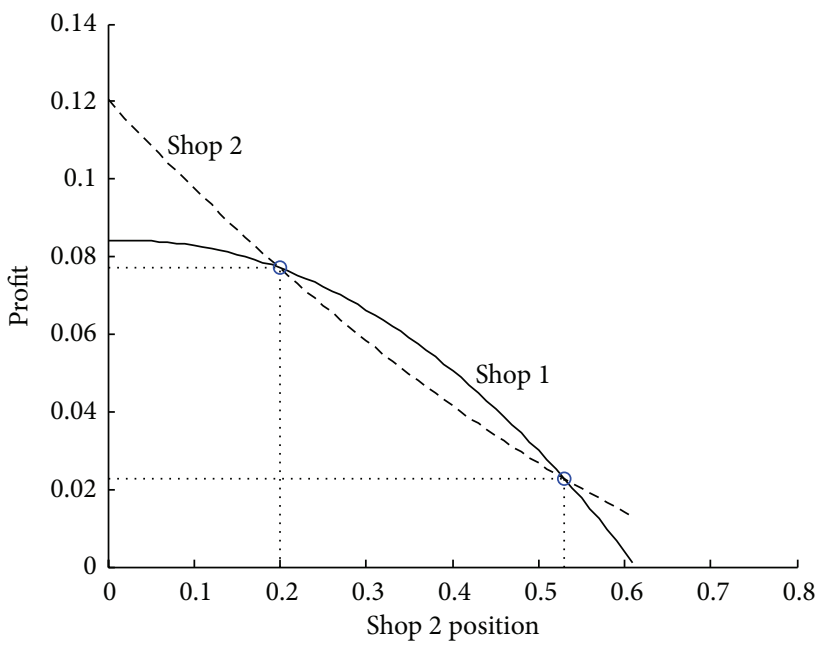

FIGURE 6: Equilibrium profits varying with shop 1's location when shop 2 locates at $0.2(b=0.2)$.

5.2. Online Shops Locating at Arbitrary Positions of the Line City. Under the demand effect, the two shops will locate at the center of the line city. However, the delivery logistics cost will "pull" the shops from the center. Figure 6 presents the shops' equilibrium profits varying with shop 2's location when shop 1 locates at $0.2(a=b=0.2$ indicates the equilibrium locations for the two shops). When shop 1 moves to shop 2, their profits all decrease, although it seems that shop 1 earns more than shop 2. When shop 1 moves to shop 2, shop 2 with the fixed location chooses to decrease its price for attracting consumer demands, and the equilibrium price curves of the two shops are presented in Figure 7.

The profit of shop 1 is shown in Figure 8 with variable locations of shops 1 and 2. When the shop moves towards the center, the profit decreases until the shop is close enough to another shop. And there is an interesting phenomenon revealed by the experiment that when the location of one shop is fixed, the other shops moving toward the center 


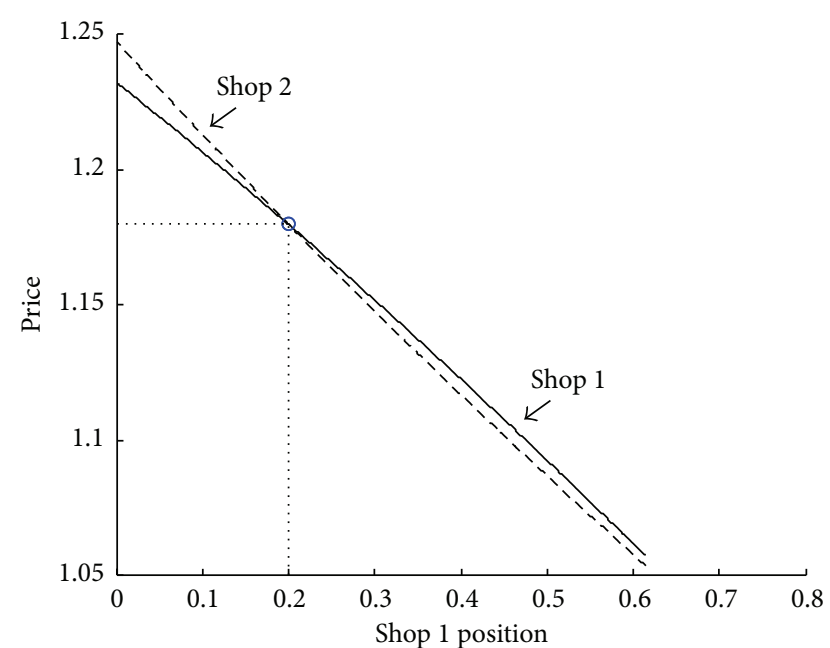

FIGURE 7: Equilibrium prices varying with shop l's location when shop 2 locates at $0.2(b=0.2)$.

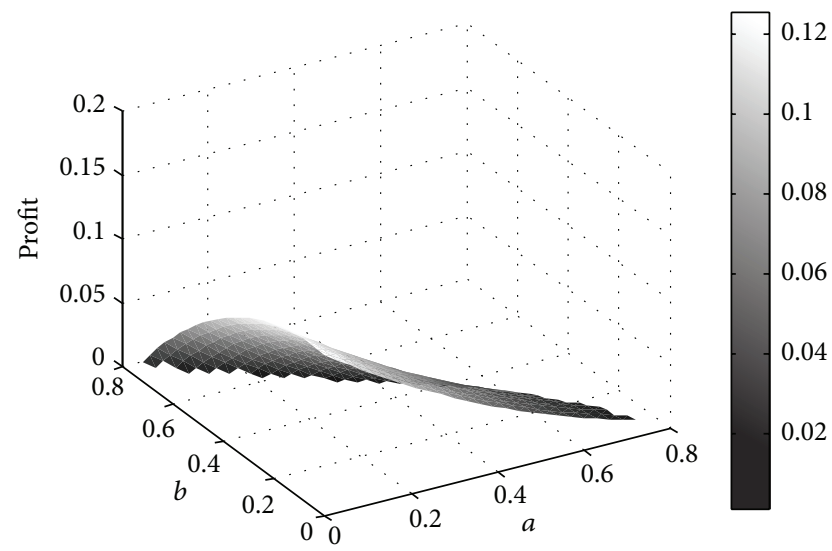

FIGURE 8: Shop 1's equilibrium profit varying with locations of two shops.

promote the profit of the fixed shop. When the shops move close to each other, the prices arise because the shops do not necessarily attract additional consumers by decreasing the prices. This variety of price will also benefit another fixed shop and leads to the peak point in the surface in Figure 8. Furthermore, when the production cost changes and the profit does not change, they can be the same as seen in Figure 8, because both shops sell homogeneous products.

Figure 9 shows the profit surfaces of both shop 1 and shop 2 from two angles of view. The intersection of the two surfaces is the Nash equilibrium profit line associated with the shops, and it is formed when the distances of the shops to the two ends of the city are equal. When the relative locations of the shops are not equal, the shop at disadvantageous location could move to the equilibrium location to get more profit and simultaneously decrease the competitor's profit.

Figure 10 depicts the equilibrium profit varying with the shops' locations and the unit waiting cost, while Figure 11

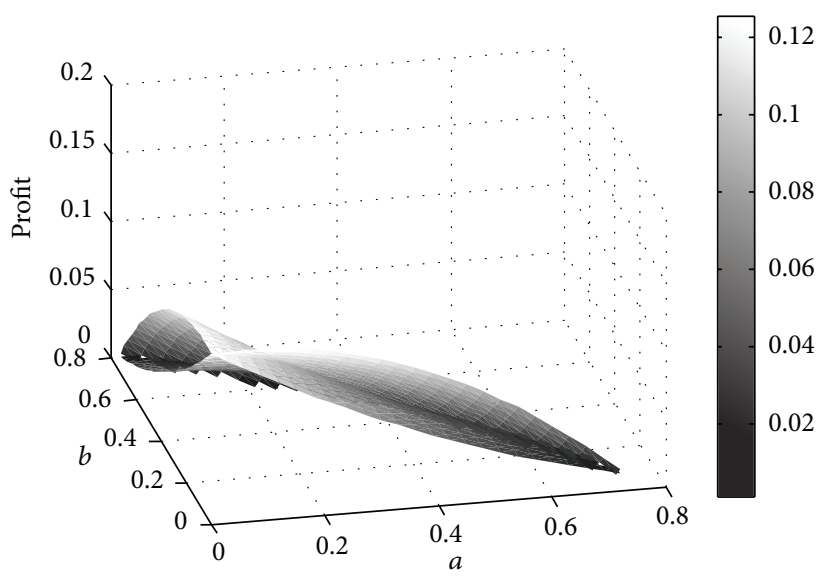

FIGURE 9: Equilibrium profit varying with locations of two shops.

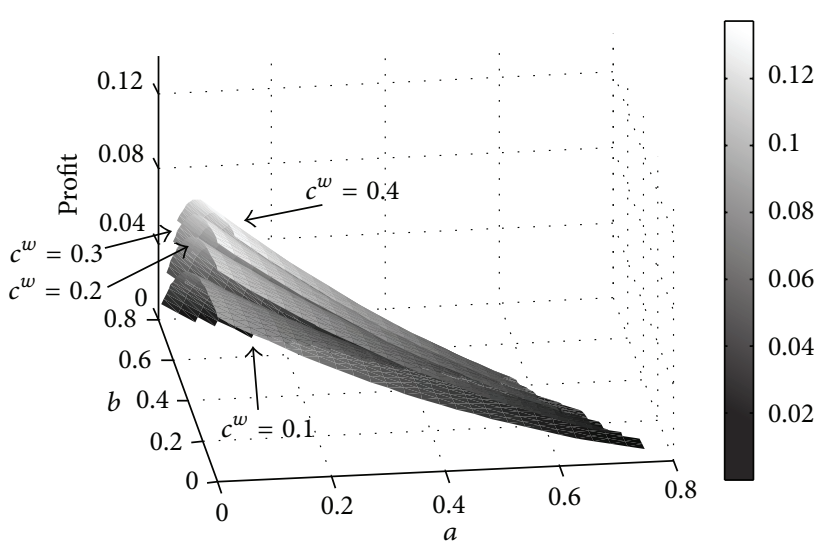

FIgURE 10: Equilibrium profit varying with shop 1's location $(a)$ and unit waiting cost $\left(c^{w}\right)$.

presents the equilibrium profit varying with the shops' locations and the unit delivery logistics cost. As a comparison result, the effect of unit waiting cost on the profit is bigger than the unit delivery logistics cost. The profit can be improved by decreasing delivery logistics cost and increasing the delivery service quality (which helps to decrease the waiting cost).

\subsection{Shops Locating at Arbitrary Positions for Mixed Online} and Offline Demands. In the following demonstration of the model considering online and offline demands, the default parameters are set as follows: the unit delivery logistics cost for online demand, $c^{d}=0.2$; the unit waiting cost for online demand, $c^{w}=0.2$; the unit production cost of goods, $c=1$; the ratio of online demand, $c^{\text {on }}=0.5$; the unit travelling cost of consumers for offline demand, $t=0.2$.

Figures 12, 13, and 14 reveal the effects of locations and ratios of online demands or unit waiting costs on the equilibrium profits. Increasing the ratio of online demand or unit waiting cost improves the equilibrium profits. 


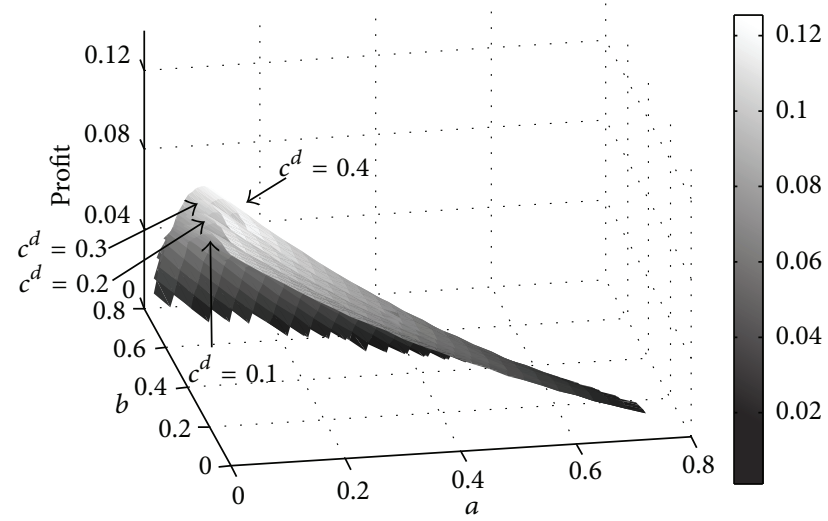

FIGURE 11: Equilibrium profit varying with shop 1's location $(a)$ and unit delivery logistics cost $\left(c^{d}\right)$.

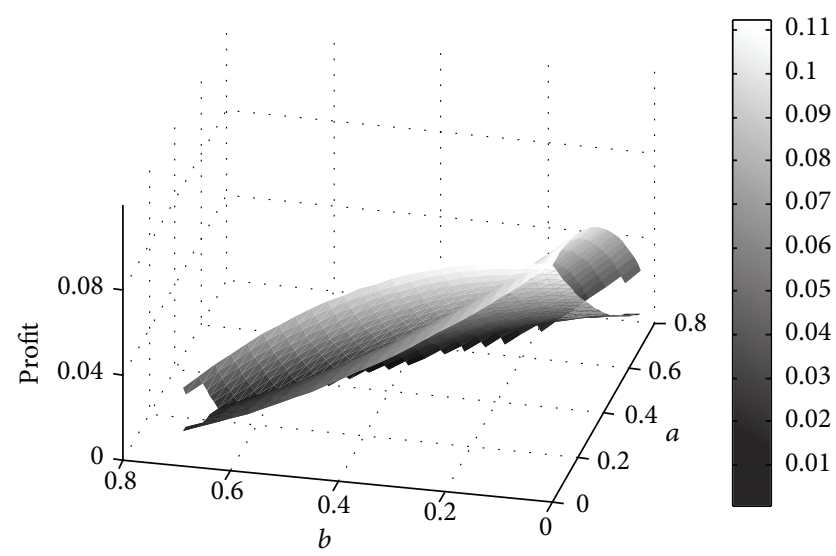

FIGURE 12: Equilibrium profit varying with shops' locations $\left(c^{\text {on }}=\right.$ $0.5)$.

\section{Conclusion}

Traditional merchants are facing offline and online demands that are challenging the business and service modes. Activated by the new business mode of combining offline and online sales in the fast food industry, this study examines the effects of the mode on the competition based on the Hotelling model. Under the demand effect, the shop stands will locate at the center in a line city in the Hotelling model that only considers the consumers' logistics cost traveling to the shops. In the extended model for the offline and online demands, the shops undertake the delivery logistics cost for the online orders, whereas the consumers' waiting cost will affect their choices of shops called. Therefore, the main contributions of this study involve the following features: considering online and offline demands in an extended Hotelling model, considering consumers' travelling cost to shops for offline demand and shops' delivery logistics cost for online demand, and considering the effect of consumers' waiting cost for online orders on the indifferent shop location. As for the future research direction, first, the parameters used in the study should be further verified by empirical studies. Second, this study does not consider the demands dependent on the

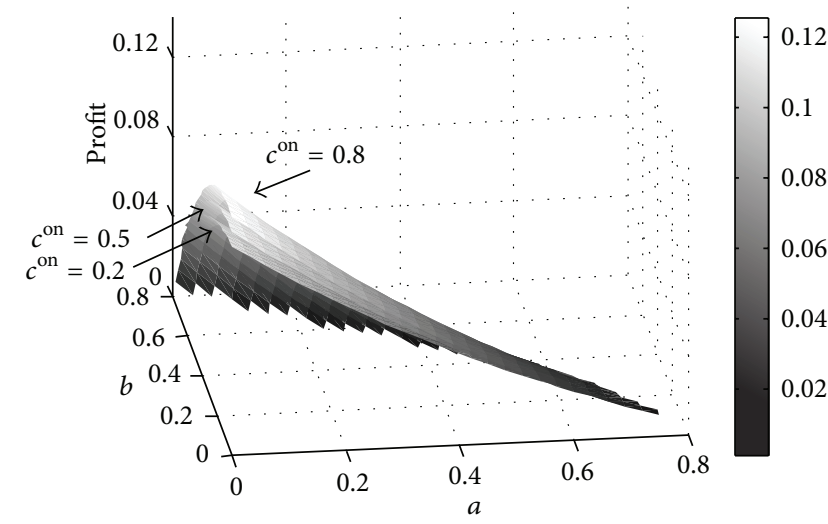

FIGURE 13: Equilibrium profit varying with shops' locations for three ratios of online demands $\left(c^{\text {on }}=0.2,0.5,0.8\right)$.

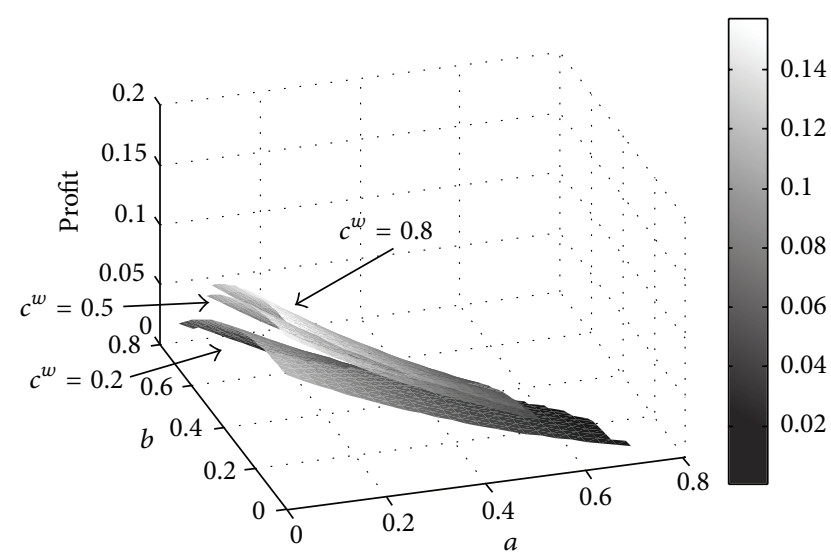

FIGURE 14: Equilibrium profit varying with shops' locations for three unit waiting costs $\left(c^{w}=0.2,0.5,0.8\right)$.

online sales mode, which is a practical feature of online and offline business. Third, the formulation for line city could be extended for real urban scenarios.

\section{Conflict of Interests}

The authors declare that there is no conflict of interests regarding the publication of this paper.

\section{Acknowledgments}

This study is partially supported by the National Natural Science Foundation of China (71101088, 71471109, 71171129, and 71390521), the National Natural Science Foundation of Jiangsu (09KJA520001), the Science Foundation of Ministry of Education of China and Shanghai (20113121120002, 14YZ100, 20123121110004, 13SG48, and 09YJA630072), the Science and Technology Commission of Shanghai (12ZR1412800, 12510501600), and the Graduate Innovation Foundation of Shanghai Maritime University (2014ycx012). 


\section{References}

[1] J. Chu, M. Arce-Urriza, J.-J. Cebollada-Calvo, and P. K. Chintagunta, "An empirical analysis of shopping behavior across online and offline channels for grocery products: the moderating effects of household and product characteristics," Journal of Interactive Marketing, vol. 24, no. 4, pp. 251-268, 2010.

[2] H. Hotelling, "Stability in competition," Economic Journal, vol. 39, no. 10, pp. 41-57, 1929.

[3] V. Shankar, A. K. Smith, and A. Rangaswamy, "Customer satisfaction and loyalty in online and offline environments," International Journal of Research in Marketing, vol. 20, no. 2, pp. 153-175, 2003.

[4] W.-S. Kwon and S. J. Lennon, "What induces online loyalty? Online versus offline brand images," Journal of Business Research, vol. 62, no. 5, pp. 557-564, 2009.

[5] S. M. C. Loureiro and H. Roschk, "Differential effects of atmospheric cues on emotions and loyalty intention with respect to age under online/offline environment," Journal of Retailing and Consumer Services, vol. 21, no. 2, pp. 211-219, 2014.

[6] T. Kollmann, A. Kuckertz, and I. Kayser, "Cannibalization or synergy? Consumers' channel selection in online-offline multichannel systems," Journal of Retailing and Consumer Services, vol. 19, no. 2, pp. 186-194, 2012.

[7] T. Ahn, S. Ryu, and I. Han, "The impact of the online and offline features on the user acceptance of Internet shopping malls," Electronic Commerce Research and Applications, vol. 3, no. 4, pp. 405-420, 2004.

[8] R. Z. Farahani, S. Rezapour, T. Drezner, and S. Fallah, "Competitive supply chain network design: an overview of classifications, models, solution techniques and applications," Omega, vol. 45, pp. 92-118, 2014.

[9] D. Grewal, R. Janakiraman, K. Kalyanam, and P. K. Kannan, "Strategic online and offline retail pricing: a review and research agenda," Journal of Interactive Marketing, vol. 24, no. 2, pp. 138154, 2010.

[10] J. Barney, M. Wright, and D. J. Ketchen Jr., “The resource-based view of the firm: ten years after 1991," Journal of Management, vol. 27, no. 6, pp. 625-641, 2001.

[11] G. Papachristos, "Transition inertia due to competition in supply chains with remanufacturing and recycling: a systems dynamics model," Environmental Innovation and Societal Transitions, vol. 12, pp. 47-65, 2014.

[12] S. Rezapour and R. Z. Farahani, "Supply chain network design under oligopolistic price and service level competition with foresight," Computers \& Industrial Engineering, vol. 72, pp. 129142,2014

[13] A. Nagurney, M. Yu, J. Floden, and L. S. Nagurney, "Supply chain network competition in time-sensitive markets," Transportation Research Part E, vol. 70, pp. 112-127, 2014.

[14] H. Gao, J. Hu, V. Mazalov, A. Shchiptsova, L. Song, and J. Tokareva, "Location-price game-theoretic model and applications in transportation networks," Procedia Computer Science, vol. 31, pp. 754-757, 2014.

[15] P. Godinho and J. Dias, "Two-player simultaneous location game: preferential rights and overbidding," European Journal of Operational Research, vol. 229, no. 3, pp. 663-672, 2013.

[16] D. Fotakis and C. Tzamos, "Winner-imposing strategyproof mechanisms for multiple facility location games," Theoretical Computer Science, vol. 472, pp. 90-103, 2013.
[17] P. M. Reyes, "Logistics networks: a game theory application for solving the transshipment problem," Applied Mathematics and Computation, vol. 168, no. 2, pp. 1419-1431, 2005.

[18] C. d'Aspremont, J. Jaskold Gabszewicz, and J.-F. Thisse, "On Hotelling's 'Stability in competition,' Econometrica. Journal of the Econometric Society, vol. 47, no. 5, pp. 1145-1150, 1979.

[19] S. C. Salop, "Monopolistic competition with outside goods," The Bell Journal of Economics, vol. 10, no. 1, pp. 141-156, 1979.

[20] H. Larralde, J. J. Stehlé, and P. Jensen, "Analytical solution of a multi-dimensional Hoteling model with quadratic transportation costs," Regional Science and Urban Economics, vol. 39, no. 3, pp. 343-349, 2009.

[21] T. Tabuchi and J.-F. Thiees, "Asymmetric equilibria in spatial competition," International Journal of Industrial Organization, vol. 13, no. 2, pp. 213-227, 1995.

[22] A. D. Palma, V. Ginsburgh, and J.-F. Thisse, "On existence of location equilibria in the 3-firm Hotelling problem," The Journal of Industrial Economics, vol. 36, no. 2, pp. 245-252, 1987.

[23] B. Eaton, "Spatial competition revisited," The Canadian Journal of Economics, vol. 5, no. 2, pp. 268-278, 1972.

[24] A. Shaked and J. Sutton, "Relaxing price competition through product differentiation," The Review of Economic Studies, vol. 49, no. 1, pp. 3-13, 1982.

[25] K.-D. Wey and S.-C. Hong, "Refuse-derived fuel as a secondary energy in Taiwan-using Hotelling space allocation model," Resources Policy, vol. 31, no. 4, pp. 204-210, 2006.

[26] F. Blosh and D. Manceau, "Persuasive advertising in Hotelling's model of product differentiation," International Journal of Industrial Organization, vol. 17, no. 4, pp. 557-574, 1999.

[27] B. G. Mariñoso, "Technological incompatibility, endogenous switching costs and lock-in," The Journal of Industrial Economics, vol. 49, no. 3, pp. 281-198, 2001. 


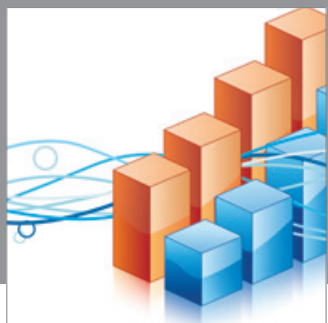

Advances in

Operations Research

mansans

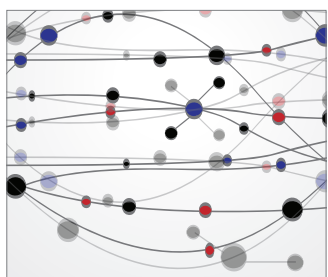

The Scientific World Journal
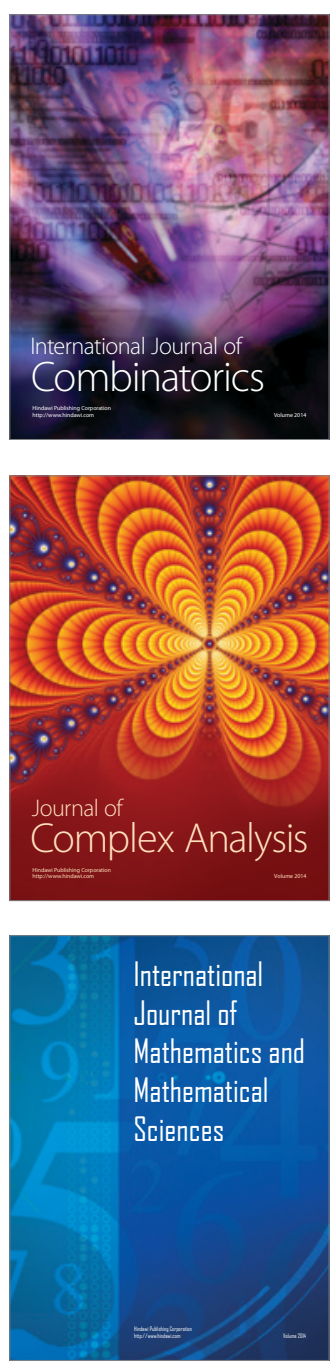
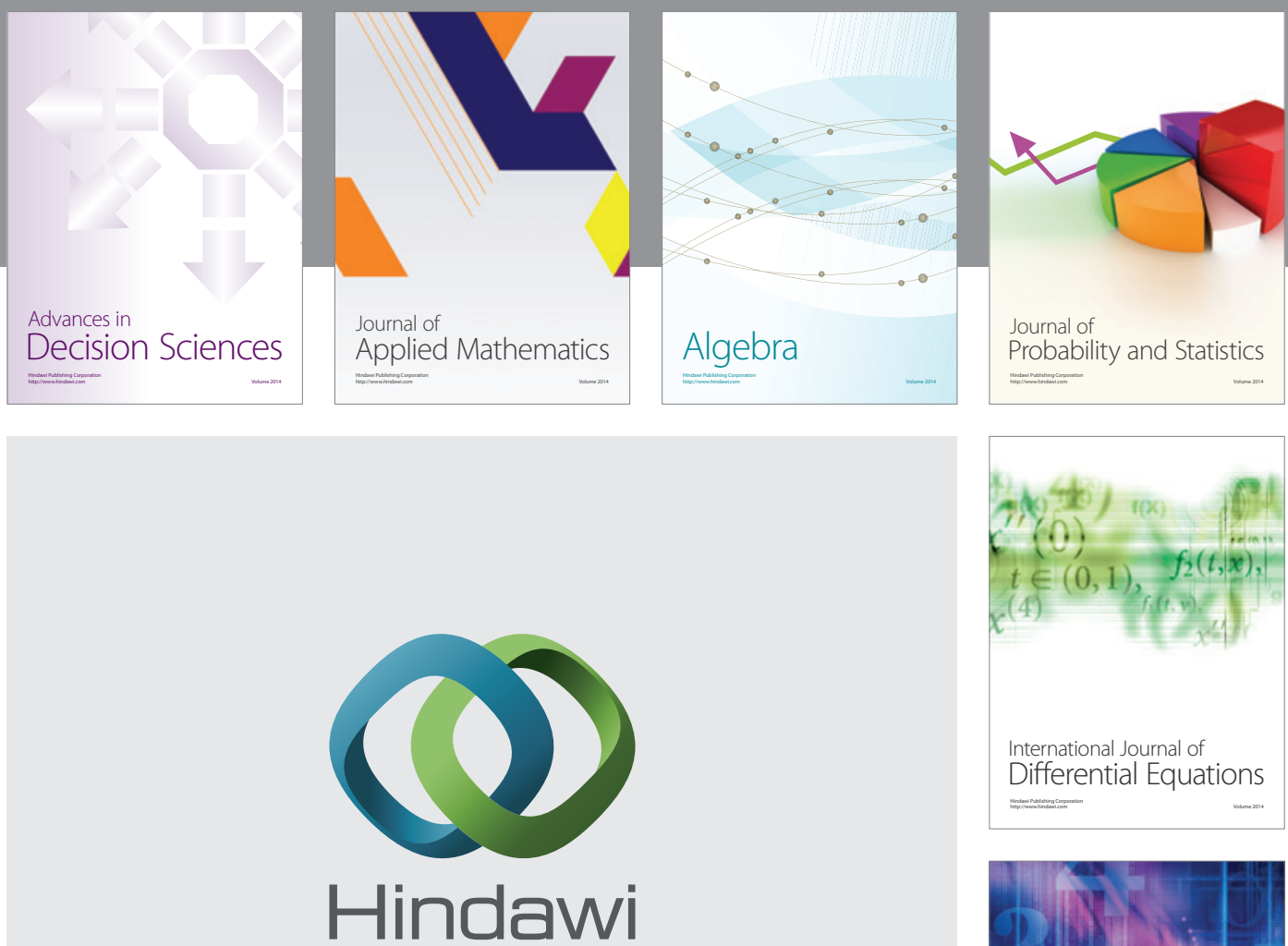

Submit your manuscripts at http://www.hindawi.com
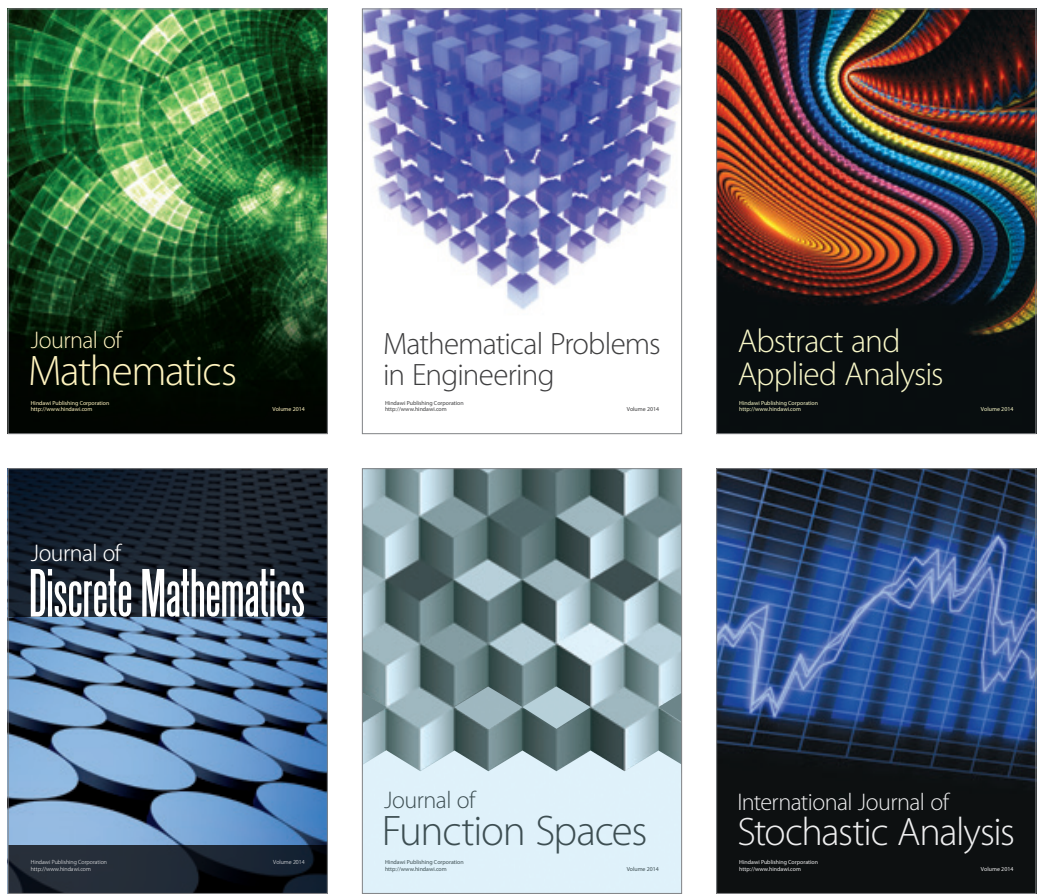

Journal of

Function Spaces

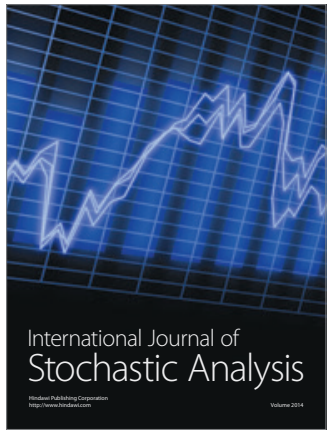

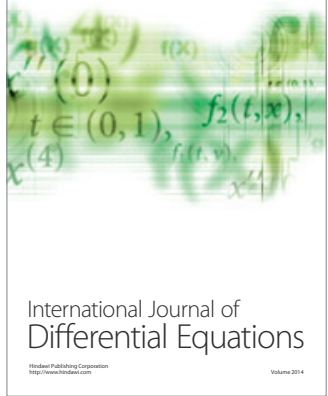
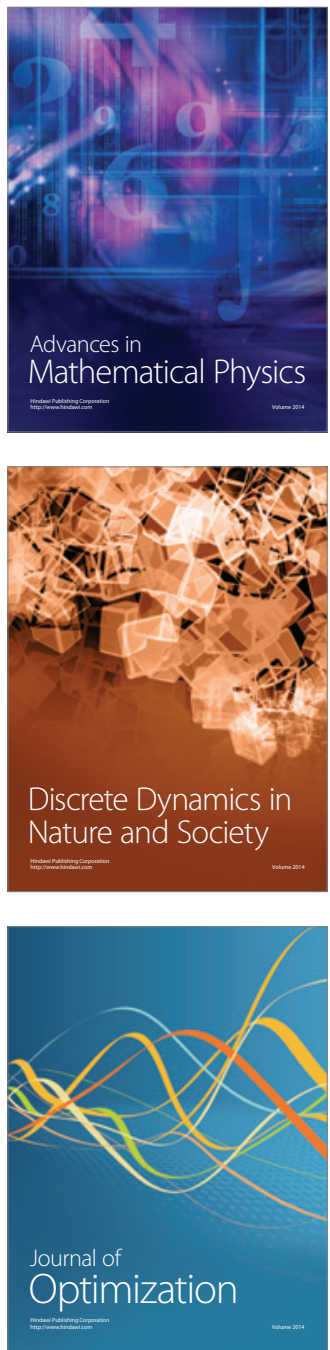